\title{
Chocolate, Colour and Consideration: An Exploratory Study of Consumer Response to Packaging Variation in the South African Confectionery Sector
}

\author{
Justin Beneke $^{1}$, Victoria Floyd ${ }^{1}$, Caroline Rono ${ }^{1} \&$ Kimryn Sherwood ${ }^{1}$ \\ ${ }^{1}$ School of Management Studies, Faculty of Commerce, University of Cape Town, South Africa \\ Correspondence: Justin Beneke, School of Management Studies, University of Cape Town, South Africa. Tel: \\ 27-21-650-4392. E-mail: Justin.Beneke@uct.ac.za
}

Received: December 2, 2014 Accepted: December 22, $2014 \quad$ Online Published: January 26, 2015

doi:10.5539/ijms.v7n1p55

URL: http://dx.doi.org/10.5539/ijms.v7n1p55

\begin{abstract}
Color has become increasingly influential as marketers seek to unlock the potential this factor has on behavioural decisions, in part due to colour being the first product attribute a consumer's brain registers when looking at a product. However, minimal academic research has been undertaken to investigate this function in an emerging market context. This exploratory study sets out to examine how thecolourof packaging of chocolate products affects consumers' purchase intent, both in terms of spontaneous response and brand loyalty. A consumer survey was conducted through a mall-intercept approach using a sample of 161 respondents. The Friedman and Mann Whitney $U$ tests were conducted in order to compute the data generated within this study. The research concludes that colour holds the potential to influence a consumer's purchase behaviour of chocolate, with purple far more influential than orange, for example. Moreover, this effect was found to be consistent across low and high income groups. The results underscore the importance of colour and suggest marketers and retailers would be well advised to consider the associations between packaging colour and consumer response.
\end{abstract}

Keywords: purchase intention, impulse buying, brand loyalty, colour, packaging, chocolate, confectionery, South Africa

\section{Introduction}

Consumers shopping at FMCG retail outlets are confronted with many different chocolate varieties from which to choose. These chocolate products come in different guises and are wrapped in differentiated packaging. Furthermore, they may be displayed in either the confectionary aisle and/or at the check out point. Chocolate brands include such names as Cadbury, Lindt, Nestle and Beacon (Zachariasen \& Schofield, 2008). In this competitive landscape, marketers must discover ways of breaking through the visual clutter of chocolate brands within the marketplace in order to be successful in selling their products (Garber, Burke, \& Jones, 2000).

This is underscored by the fact that consumers spend, on average, one-third of a second looking at each product at the point of purchase (Chavan-Patil, 2012). A powerful tool for achieving visibility is through colour as thishas the ability to communicate the product's brand through associations to consumers even when the brand name is not directly visible. Moreover, colour can also be a quality cue communicator for brands and the specific product (Chavan-Patil, 2012).

Research has shown that colour can certainly affect a consumer's purchase behaviour. Consumers carry associations that may solicit an emotional response, resulting in purchasingbehaviour (Haller, 2013). This study will investigate two types of purchasing behaviour, Impulse Buying and Brand Loyalty. Impulse buying is regarded as the unplanned purchase of a product by a consumer whereas, in contrast, brand loyalty is defined as the consumer recognition of a need and a considered response to acquire a preferred brand (McPherson, 2012). Chavan-Patil (2012) suggests that impulse buyers respond best to colours of red, orange, black and royal blue, whilst consumers exhibiting loyalty tendencies towards the brand respond best to colours such as pink, light blueand navy. This is further explored in the literature review in the following section of this paper.

It would appear that substantial research has been conducted into how colour affects consumers' purchasing behaviour, yet most of this research is centredarounddeveloped nations. To this end, there remains a need for this research in emerging markets, such as South Africa. In relation to the aforementioned, the following research 
question was formulated to guide this exploratory study:

Does the colour of packaging of chocolate products affect consumers' purchase intention in South Africa? Furthermore, are such responses contingent on income level?

Based on the research question postulated above, the following research objectives were defined:

- To determine whether colour has an impact on individuals' Brand Loyalty

- To determine whether colour has an impact an individuals' Impulse Buying

- To determine whether income level affects consumer response to colour with respect to Brand Loyalty and Impulse Buying.

The article is structured by means of a literature review to provide a conceptual overview of drivers of purchase intent, with a specific focus on impulse buying versus brand loyalty. This is followed by an overview of the research methodology employed within the study. Thereafter, the results of the statistical analysis and conclusions emanating from these findings are presented. Finally, managerial implications, limitations and areas of future research are offered.

\section{Literature Review}

The literature review considers the conceptualisation and measurement of both impulse buying and brand loyalty. Subsequently, the usage of colour in packaging and the various associations with specific colours are addressed.

\subsection{Conceptualisation and Measurement of Impulse Buying}

One of the first definitions of impulse buying, according to Kollat and Willett (1967), labeled it as an unplanned purchase or one that was unanticipated prior to entering the retail outlet. Almost three decades later, this was described by Rook and Gardner (1993) as a rapid subjective decision-making process, whereby the consumer immediately requires possession of the product. The latest and most comprehensive definition describes impulse buying as a 'transient' reaction to the exposure of products and advertising (Arens \& Rust, 2012). Thus, the fundamental definition has not fundamentally waivered from the core notion of satisfying a need or want 'on the spot'.

More specifically, Karbasivar and Yarahmadi (2011) contend that such impulsiveness is underpinned by the following five characteristics:

(1) A sudden and spontaneous desire to act

(2) A state of psychological disequilibrium

(3) The onset of psychological conflict and struggle

(4) A reduction in cognitive evaluation

(5) A lack of regard for the consequences of impulse buying.

Similarly, Arens and Rust (2012) contend that the core elements of impulse buying are that the decision-making process is unreflective i.e., there is no engaging in evaluation and there is a lack of consideration for consequences. Likewise, according to Kuikka and Laukkanen (2012), the impulse to purchase emanates from hedonic value and is therefore a complex subconscious urge or reaction that is difficult to track and understand as consumers are not necessarily making consistent decisions.

Spontaneous response may be contrasted with brand loyalty, as discussed below.

\subsection{Conceptualisation and Measurement of Brand Loyalty}

Brand loyalty has traditionally been considered a situation in which consumers purchase a brand repeatedly. Olson and Jacoby (1971) provided one of the most notable contributions to the field through distinguishing betweentwo distinct types of brand loyalty: behavioural and attitudinal. This notion postulated that loyalty is a behaviouraloutcome and not the reason for it (Jacoby \& Kyner, 1973). In this respect, attitudinal loyalty is recognised to be the more authentic loyalty, implying a true commitment to a specific brand (Bloemer \& Kasper, 1994).

Brand loyalty, in either form, can be seen as a composition of both previous and future behavioural intent. For brand loyalty to be established, an individual must have consciously made a particular selection choice previously, with the intention to repeatthe purchase decision in the foreseeable future (Jacoby \& Kyner, 1973).

According to Bloemer and Kasper (1994), there are six necessary and collectively sufficient conditions that serve to define and measure brand loyalty. These six conditions are: 
(1) The purchasing preference a consumer holds

(2)His/her behavioural response

(3) The period of time involved

(4) The presence of some decision-making unit

(5) The option of buying more than one brand

(6) A function of psychological processes whereby consumers compare and evaluate competing brands

Having discussed the two different aspects of purchase intent, spontaneous response and brand loyalty, attention is now turned to the use of colour in packaging, as well as the various associations with specific colours. These are addressed below.

\subsection{The Use of Colour in Packaging}

Packaging was originally created for the purpose of creating a 'protective barrier' to avoid damage during transportation, storage, etc. Today, packaging also forms part of the product, representing a means of marketing the product to the consumer base. Due to the plethora of competing FMCG brands and the importance placed on effective packaging, this particular market segment is often viewed as the backbone of the packaging printing industry (Brunner, 2007).

The colour scheme of the packaging is the first attribute of a product that a consumer's brain registers, before typography or images (Haller, 2013). This can assist FMCG manufacturers, such as chocolate suppliers, to establish a visual identity for the brand, attract consumers to their product, and create a 'unique' position of their brand amongst competitors (Labrecque \& Milne, 2011). Here, Labrecque and Milne (2011) contend that colour can convey intrinsic meaning to consumers that aids brand recognition (Abri, Olazabal, \& Cava, 2009) and communicates the desired image (Bottomley \& Doyle, 2006).

Colour has been found to exhibit two different associations, namely natural associations, as well as psychological and cultural associations. Natural colour associations occur when colour links to objects in nature, such as associating blue with the sky and yellow with the sun (Loyalty Square, 2010). In contrast, psychological or cultural colour associations occur when colours hold different meanings in particular cultural contexts. For example, black is considered to be the colour of death in the western world whilst, in other parts of the world, white is considered to hold that particular significance (Loyalty Square, 2010).

Some researchers put forward the notion of a "subliminal tool kit", suggesting that the colour of the packaging has the ability to influence spontaneous response, as well as brand loyalty (DeLise, 2012). Absorbed subconsciously, these messages can, in turn, evoke emotions and impact purchase intent (Chavan-Patil, 2012). This is particularly interesting to marketers as sixty to seventy percent of adult purchase decisions are reported to occur at the point of purchase (DeLise, 2012). Moreover, this underscores the importance of colour, notably in a competitive merchandise category such as the chocolate confectionary segment.

\subsection{Colour Associations}

In order to create effective brand positioning, marketers need to understand relevant colour psychology and how this impinges uponconsumers' purchase intent.

As noted in the introduction, Chavan-Patil (2012) found that impulse buyers responded best to red, orange and black. Table 1 lists these colours and the associated qualities and emotions.

Table 1. Impulse purchase colours with associated qualities and emotions

\begin{tabular}{ll}
\hline Colour & Qualities and Emotions \\
\hline Red & Energy, passion, excitement, increased heart rate, speed, danger and increased urgency \\
Orange & Warmth, vibrancy, aggression and creates a call to action \\
Black & Power, sleekness, mystery, elegance and sophistication \\
\hline
\end{tabular}

Sources: KissMetrics (2014) and Chavan-Patil (2012).

McPherson (2005) describes brand loyalty as the act of intentionally buying a particular brand in response to a need or problem. The choice thereof is usually consistent (Chavan-Patil, 2012). Brand loyalty may become unhinged if dramatic changes are effected to the colour scheme or packaging. This is due to the fact that these consumers develop an attachment to the brand's visual identity (Labrecque \& Milne, 2011). As noted in the 
introduction, consumers exhibiting traits of brand loyalty are inclined to respond best to the colours of pink, light blue and navy (Chavan-Patil, 2012). Table 2 describes the colours to which brand loyalists are most responsive, as well as the respective qualities and emotions.

Table 2. Brand loyaltycolours with associated qualities and emotions

\begin{tabular}{ll}
\hline Colour & Qualities and Emotions \\
\hline Pink & Soft, sweet, nurturing, secure, romantic and feminine \\
Blue & Trust, reliability, security, refreshing and cool \\
\hline
\end{tabular}

Sources: KissMetrics (2014) and Chavan-Patil (2012).

\section{Methodology}

The methodology component of this article addresses how the data was collected, synthesised and analysed in order to address the specific research objectives.

\subsection{Research Method and Sample Design}

This study considers the effect of colouron the constructs of brand loyalty and impulse buying, in addition to whether income group has an influence in affecting this association.

The mall-intercept survey method involves the collection of data in which a random sample of respondents passing through a shopping mall are intercepted and asked to participate in the study (Maholtra, 2010; Brown, Churchill \& Suter, 2009). The mall-intercept survey method was chosen as it permitted the researchers to reach respondents in a location where they naturally congregate to perform retail activities. It also appealed to the researchers, as it was deemed to be a quick, convenient and low cost data collection method.

A traditional sampling approach without replacement was used, meaning that the test units were only used once. These test units were obtained using a non-probability, convenience sample, whereby the selection is arbitrary and without favour although, ultimately, left in the hands of the researchers (Maholtra, 2010). The survey was administered to a total of 161 respondents within six mainstream supermarket stores in South Africa.

\subsection{Research Instrument and Measurement Scales}

The questionnaire was designed in accordance with that used by Arens and Rust (2012). The measurement scales were adapted and used to capture the pivotal constructs in this study i.e., spontaneous response and brand loyalty.

After being exposed to the relevant treatment, the respondents were asked to complete the questionnaire, comprised of three sections. In the first section, consumers rated the impulsiveness of their decision-making process using the product-specific impulsiveness scale (Arens \& Rust, 2012; Jones et al., 2003; Rook \& Fisher, 1995). In the second section, respondents rated their brand loyalty using the loyalty intent scale (Zeithaml, Berry, \& Parasuraman, 1996). The statements of intent were answered in reference to images of confectionery that only differed by colour.

Traditional colours, associated with brand loyalty and impulse buying, were featured. Red and orange were included due to their association with impulse buying, whereas blue and purple were included due to their association with brand loyalty. The third section was comprised of questions pertaining to key respondent demographics.

The basic scale design used in this study was that of a Likert scale. This scale type was advantageous in that it is easy to construct, administer and comprehend. Thus, a five-point Likert scale ranging from 'strongly disagree' (1) to 'strongly agree' (5) was implemented to measure impulse buying and brand loyalty. Table 3 shows the specific items used in the questionnaire to measure the two constructs.

Table 3. Constructs and items used

\begin{tabular}{ll}
\hline Construct & Items used \\
\hline Impulse Buying & I made this choice spontaneously. \\
& I carefully planned my purchase decision. \\
& I made the choice according to how I felt at the moment. \\
& I am likely to encourage my friends and relatives to purchase it. \\
Brand Loyalty & I am likely to buy this product over the next few months. \\
& I would consider buying it as my first choice when thinking of chocolate.
\end{tabular}


Thus, it can be seen by reflecting on the above scale items, that the construct of impulse buying measures the extent to which consumers make spur of the moment, unplanned decisions to buy. The construct of brand loyalty measures the extent of the faithfulness of consumers to a particular brand.

As highlighted above, this was congruent with the measurement scales adopted by Arens and Rust (2012) in their study. Table 4 lists the Cronbach Alpha's obtained in this study relative to those captured in the Arens and Rust (2012) study.

Table 4. Cronbach Alpha's of summated scales

\begin{tabular}{lll}
\hline Summated Scale & Cronbach Alpha: & Cronbach Alpha: \\
& Arens and Rust (2012) & This Study \\
\hline Impulse Buying & 0.88 & 0.62 \\
Brand Loyalty & 0.95 & 0.78 \\
\hline
\end{tabular}

\subsection{Fieldwork and Data Analysis Techniques}

During collection of this data, the fieldworkers showed respondents each of the four different images and granted them time to answer the questions pertaining to each colour. This one-on-one interaction allowed respondents to seek clarification on the questions, where necessary. The average time taken to conduct each questionnaire was approximately ten to fifteen minutes. In general, most of the respondents expressed willingness to participate in the study, with only a small number of declines. This primary data was captured into a spreadsheet and, thereafter, used to statistically analyse the effect of colour on brand loyalty and impulse buying and, subsequently, any potential deviations across income groups.

In order to investigate the impact of various colours on purchase intent, and the influence of various demographic variables in the process thereof, the Friedman and Mann Whitney $U$ tests were utilised.

The Friedman test is the non-parametric alternative to the one-way ANOVA with repeated measures. It is used to test for differences between groups when the dependent variable being measured is ordinal. It can also be used for continuous data that has violated the assumptions necessary to run the one-way ANOVA with repeated measures i.e. data that has marked deviations from normality (Laird, 2014a). This was utilised to scrutinise the extent to which colour impacted purchase intent.

The Mann Whitney U test, the non-parametric equivalent of the independent samples t-test (Laird, 2014b), was used to ascertain the significance of income group in influencing whether a consumer was inclined to associate a particular colour with either spontaneous response or brand loyalty tendencies.

The statistical analysis was performed using the IBM SPSS version 22 software package.

\section{Findings}

\subsection{Data Normality}

The Kolmogorov-Smirnov test was used to test for normality with the following hypothesis:

$\mathrm{H}_{0}$ : The data is normally distributed.

$\mathrm{H}_{\mathrm{A}}$ : The data is not normally distributed.

Table 5. Tests for data normality

\begin{tabular}{llllll}
\cline { 3 - 5 } & & \multicolumn{2}{l}{ Descriptives } & \multicolumn{2}{c}{ Kolmogorov-Smirnov Test } \\
\cline { 3 - 6 } & & Skewness & Kurtosis & F-Statistic & Significance Value \\
\hline \multirow{3}{*}{ Spontaneous } & Red & $-0.63-0.19$ & $-0.16-0.38$ & 0.10 & 0.00 \\
& Orange & $-0.05-0.19$ & $-0.01-0.38$ & 0.10 & 0.00 \\
& Blue & $-0.05-0.19$ & $-0.18-0.38$ & 0.09 & 0.00 \\
\multirow{3}{*}{ Brand Loyal } & Purple & $-0.42-0.19$ & $-0.17-0.38$ & 0.08 & 0.01 \\
Scales & Red & $-0.23-0.19$ & $-0.15-0.38$ & 0.10 & 0.00 \\
& Orange & $-0.98-0.19$ & $-0.39-0.38$ & 0.16 & 0.00 \\
& Blue & $-0.09-0.19$ & $-0.89-0.38$ & 0.09 & 0.00 \\
\hline
\end{tabular}


According to the significance values in Table 5, ranging between 0.00 and 0.01 , the null hypothesis of normality may be safely rejected at the $5 \%$ significance level across the board, indicating that the data is not normally distributed. The skewness values ranged between -1 and 1 , while all the Kurtosis values ranged between -1.5 and 1.5. The latter measures, however, are deemed to be within normative bounds.

\subsection{The Impact of Colour on Spontaneous Response}

As highlighted above, the Friedman test was used to test for differences between group means. Tables 6 to 8 reflect the responses to the statements testing spontaneous response to the chocolate bars in the four different guises (i.e., red, orange, blue and purple). It should be noted that the responses to Item 2 in Table 7 were reverse coded due to the inverted wording of the original statement.

Table 6. Spontaneous response item 1: "I made this choice spontaneously"

\begin{tabular}{llllll}
\hline Colour & $N$ & Mean & Standard Deviation & Rank & Sig. \\
Red & 161 & 3.155 & 1.4299 & 3 & \\
Orange & 161 & 2.236 & 1.2870 & 4 & \\
Blue & 161 & 3.292 & 1.3539 & 2 & .000 \\
Purple & 161 & 3.373 & 1.4397 & 1 & \\
\hline
\end{tabular}

Table 7. Spontaneous response item 2 - reverse coded: "I carefully planned my purchase decision"

\begin{tabular}{llllll}
\hline Colour & $N$ & Mean & Standard Deviation & Rank & Sig. \\
\hline Red & 160 & 2.662 & 1.3913 & 2 & \\
Orange & 160 & 2.312 & 1.3699 & 4 & \\
Blue & 160 & 2.631 & 1.4905 & 3 & .005 \\
Purple & 160 & 2.806 & 1.4209 & 1 & \\
\hline
\end{tabular}

Table 8. Spontaneous response - item 3: "I made the choice according to how I felt at the moment"

\begin{tabular}{llllll}
\hline Colour & $N$ & Mean & Standard Deviation & Rank & Sig. \\
\hline Red & 161 & 3.677 & 1.3491 & 1 & \\
Orange & 161 & 2.832 & 1.4197 & 4 & \\
Blue & 161 & 3.391 & 1.3655 & 3 & .000 \\
Purple & 161 & 3.615 & 1.3741 & 2 & \\
\hline
\end{tabular}

Respondents were generally agreeable to the notion of the colours red, blue and purple stimulating spontaneous response in favour of purchasing chocolate confectionery at the point of sale. In this respect, orange was seen to be out of kilter with the other colours and deemed considerably less attractive in prompting spontaneous response.

Table 9 summarises the ranked order of the colours for the three statements (items) measuring spontaneous response. It can clearly be seen that purple is the strongest colour of the four in stimulating spontaneous response, whereas orange is the weakest colour. Red generally fares better than blue, with both of these colours being ranked between that of purple and orange.

Table 9. Ranked order of colours for spontaneous response

\begin{tabular}{lllll}
\hline Item / Rank & Rank 1 & Rank 2 & Rank 3 & Rank 4 \\
Item 1 & Purple & Blue & Red & Orange \\
Item 2 & Purple & Red & Blue & Orange \\
Item 3 & Red & Purple & Blue & Orange \\
\hline
\end{tabular}

\subsection{The Impact of Colour on Brand Loyalty}

Tables 10 to 12 reflect the responses to the statements testing brand loyalty with respect to the chocolate bars in the four different guises (i.e., red, orange, blue and purple). As was the case previously, the non-parametric Friedman test was implemented to compare the group means. 
Table 10. Brand loyalty item 1: "I am likely to encourage my friends and relatives to purchase it"

\begin{tabular}{llllll}
\hline Colour & $N$ & Mean & Standard Deviation & Rank & Sig. \\
\hline Red & 161 & 2.832 & 1.3145 & 3 & \\
Orange & 161 & 2.050 & 1.1281 & 4 & \\
Blue & 161 & 2.888 & 1.3555 & 2 & .000 \\
Purple & 161 & 3.112 & 1.3919 & 1 & \\
\hline
\end{tabular}

Table 11. Brand loyalty item 2: "I am likely to buy this product over the next few months"

\begin{tabular}{llllll}
\hline Colour & $N$ & Mean & Standard Deviation & Rank & Sig. \\
\hline Red & 161 & 3.242 & 1.2638 & 2 & \\
Orange & 161 & 2.050 & 1.1057 & 4 & \\
Blue & 161 & 3.093 & 1.2590 & 3 & .000 \\
Purple & 161 & 3.366 & 1.3679 & 1 & \\
\hline
\end{tabular}

Table 12. Brand loyalty item 3: "I would consider buying this as my first choice when thinking of chocolate"

\begin{tabular}{llllll}
\hline Colour & $N$ & Mean & Standard Deviation & Rank & Sig. \\
Red & 161 & 3.012 & 1.3829 & 2 & \\
Orange & 161 & 1.925 & 1.1322 & 4 & \\
Blue & 161 & 2.994 & 1.3393 & 3 & .000 \\
Purple & 161 & 3.267 & 1.4176 & 1 & \\
\hline
\end{tabular}

Similar to the case of spontaneous response, respondents were generally agreeable to the notion of red, blue and purple underpinning brand loyalty in favour of the ongoing purchase of these chocolate confectionery products. Yet again, orange was seen to be out of kilter with the other colours and deemed subordinate in fostering brand loyalty.

Table 13 summarises the ranked order of the colours for the three statements measuring brand loyalty. In keeping with the findings for spontaneous response, it can be seen that purple is consistently ranked the most powerful colour of the four in perpetuating brand loyalty, whereas orange is the weakest. Red generally fares better than blue, with both of these colours ranked between purple and orange. Again, this is largely congruent with the findings for spontaneous response.

Table 13. Ranked order of colours for brand loyalty

\begin{tabular}{lllll}
\hline Item / Rank & Rank 1 & Rank 2 & Rank 3 & Rank 4 \\
\hline Item 1 & Purple & Blue & Red & Orange \\
Item 2 & Purple & Red & Orange & Orange \\
Item 3 & Purple & Red & Blue \\
\hline
\end{tabular}

\subsection{The Influence of Income Group on Response to Colour}

As highlighted in the methodology section, the Mann Whitney $U$ test was used to ascertain the significance of income group in influencing whether a consumer was inclined to associate a particular colour with either spontaneous response or brand loyalty inclinations.

It can be seen in Table 14 that, in the vast majority of cases (i.e. $21 / 24$ or $87.5 \%$ ), colour was not found to a contributing factor in this respect. Moreover, no consistent trends were evident as the three instances of bias were spread over three different colours (i.e. red, orange and purple). Thus, there is overwhelming evidence to suggest that income group does not play a role in the perception of colour driving purchase intent. 
Table 14. Significance of income group

\begin{tabular}{lllllll}
\hline Colour / Item & S.R. 1 & S.R. 2 & S.R. 3 & B.L. 1 & B.L. 2 & B.L. 3 \\
\hline Red & $\mathbf{0 . 0 1 1}$ & 0.444 & 0.728 & 0.332 & 0.683 & 0.533 \\
Orange & 0.136 & 0.193 & $\mathbf{0 . 0 4 5}$ & 0.260 & 0.637 & 0.253 \\
Blue & 0.610 & 0.096 & 0.433 & 0.699 & 0.165 & 0.290 \\
Purple & 0.180 & 0.577 & 0.171 & $\mathbf{0 . 0 4 0}$ & 0.063 & 0.159 \\
\hline
\end{tabular}

\section{Conclusions}

The focus of this study was to ascertain the effect of packaging colour in stimulating purchase intent to buy chocolate, both in terms of impulse purchases and planned purchases. Furthermore, the study considered whether there was a discernable difference in response between upper and lower income consumer groups.

\subsection{Purple Perceived as Most Conducive, and Orange Least Conducive, to the Purchasing of Chocolate Confectionery}

Purple was ranked, almost across the board, as the most influential colour in stimulating purchasing of chocolate products. This was generally followed by the colours of red and blue and, thereafter, orange. Orange was consistently ranked as the least influential of the four colours in this particular market niche. It may therefore be concluded that, generally, consumers respond most favourably to purple and least favourably to orange within the evoked set of chocolate bar considerations.

\subsection{The Colour Stimuli for Spontaneous Response and Brand Loyalty Are Not Dissimilar}

It may be said that what works for spontaneous response also appears effective in the case of brand loyalty. Although the rankings differed slightly, the broad structure of colour preferences remained very similar. For instance, purple was ranked the preferred colour in all three statements for brand loyalty whereas this was ranked first in two instances and ranked second in one instance when considering the case of spontaneous response. Therefore, it may be argued that the effect is more prevalent in the case of brand loyalty. However, it should be acknowledged that the deviation in responses is very slight and most probably inconsequential.

\subsection{No Effect of Income Group on Response to Colour}

The effect of income group was found to have a very minimal effect on colour perception. To this end, no consistent trends were evident as the three instances of bias (out of a total of 24 cases) were spread over three different colours (i.e. red, orange and purple). It may therefore be concluded that a consumer's income level has no bearing on the manner in which they respond to colours, in terms of both spontaneous response and brand loyalty.

\section{Managerial Implications}

Based on the conclusions detailed above, several inferences can be drawn, giving rise to various managerial implications for industry practitioners.

\subsection{Not All Colours Are Perceived Equal}

It was found that different colours possess different impacts on purchasing behaviour. The Friedman tests for both spontaneous response and brand loyalty revealed that the mean values for the statements probing purchase intent were indeed significantly difference. Thus, the performance of various colours cannot reasonably be considered the same. Yet, certain colours are uniformly more effective than others. In the chocolate confectionery segment, purple seems to be the colour of choice. This is likely due to the association with Cadbury, a leading brand within the category. Thus, in principle, the colour associated with the category leader may be most conducive to stimulating chocolate sales.

\subsection{Consistency in Colour Associations for Both Response Types}

As asserted above, certain colour associations were found to be consistent across response types. As such, purple led to the highest levels of both spontaneous response and brand loyalty, whereas orange led to the lowest levels of both spontaneous response and brand loyalty. This synergy suggests that underlying connotations are common to both functions. Moreover, spontaneous response on one occasion could lead to the development of brand loyalty on further shopping occasions. A distinction between the two response types might therefore not be absolute or even relevant in practice.

\subsection{Colour Associations Likely to Be Dependent on Product Category}

In the literature review, the associations with different colours were discussed. Chavan-Patil (2012) and 
KissMetrics (2014) noted that warmer colours, such as red and orange, tend to be associated with spontaneous purchasing, vibrancy and fun. In contrast, cooler colours such as blue and purple were associated with greater brand loyalty, bringing feelings of trust and comfort to the fore. Notwithstanding these interesting findings, this study suggests that the generalisation expressed above does not necessarily extend to all product categories and apply within all markets.

\section{Limitations of the Study}

This study, as is the case for any piece of research, is subject to a number of noteworthy limitations. These are mentioned below.

\subsection{Existing Brands Cannot Be 'Unseen' and 'Unfavoured'}

Whereas market research may ask respondents to acknowledge associations with colours and the feelings they induce, actual purchase behaviour may deviate quite substantially from this stated intent. The problem is compounded by specific brands that exist in a real world setting. The colour red is a perfect example. When exposed to red, individuals would automatically be reminded of noteworthy chocolates that feature red packaging, such as Kit Kat. As such, issues of entrenched preference for a particular brand, associated with a designated colour, may become conflated.

\subsection{Environmental Factors in Probing Respondents}

Time of day is likely to be a pertinent factor pertaining to an individual's decision making. A study by Chetthamrongchai and Davies (2000) revealed that consumers demonstrate different purchasing behaviours at different times of the day. Perhaps respondents who answered the questionnaire in the morning, a time seen as less conducive to chocolate consumption, may have been unenthusiastic about purchasing chocolate in general. In contrast, those answering the questionnaire at lunchtime, when chocolate is generally seen to be more suitable to consume, may have responded more assertively and positively. In order to mitigate this effect, consumers were asked to answer the questionnaire at random times throughout the day.

\subsection{The Influence of Exogenous Variables in Stimulating Purchasing Behaviour}

This study did not interrogate consumers' familiarity with the chocolate category, their consumption habits, etc. It is possible that some of those consumption statistics may have influenced their respective views and, hence, response towards certain colours. Moreover, the shopping occasion (e.g., buying of a 'thank you' gift for a colleague, a Valentine's Day gift for a loved one, etcetera) may have acted to influence the purchase decision and neutralise conventional buying behaviour. This may further serve to distort findings.

\section{Future Research Opportunities}

Future researchers working within this area could make use of direct observation and then approach the consumer (respondent), enquiring whether it was a planned or unplanned purchase. This would align colour preference with confirmed, as opposed to anticipated, purchasing behaviour.

This study looked at natural associations that consumers have with colours. Future researchers may wish to investigate the impact that the psychological or cultural associations of colour have on consumer purchasing behaviour of chocolate products. Investigating this aspect in conjunction with natural colour associations may lead to more conclusive results in determining the comprehensive effect.

Lastly, researchers investigating this research topic in future could expose respondents to a wider spectrum of colours than used in this particular study. This may shed further light on precisely which colours are best suited to chocolate packaging.

\section{References}

Arens, Z., \& Rust, R. (2012). The duality of decisions and the case for impulsiveness metrics. Journal of the Academy of Marketing Science, 40, 468-479. http://dx.doi.org/10.1007/s11747-011-0256-3

Bellenger, D. N., Robertson, D. H., \& Hirschman, E. C. (1978). Impulsive Buying Varies by Product. Journal of Advertising Research, 18, 15-18.

Berridge, K. C. (2004). Motivation Concepts in Behavioural Neuroscience. Psychology \&Behaviour, 81, 179-209.

Bloemer, J., \& Kasper, H. (1994). The complex relationship between consumer satisfaction and Brand Loyalty. Journal of Economic Psychology, 16, 311-329. http://dx.doi.org/10.1016/0167-4870(95)00007-B

Bottomley, P. A., \& Doyle, J. R. (2006). The interactive effects of colours and products on perceptions of brand logo appropriateness. Marketing Theory, 6(1), 63-83. http://dx.doi.org/10.1177/1470593106061263 
Brown, T. J., Churchill, G. A., \& Suter, T. A. (2009). Basic Marketing Research. Cencage South-Western, New York.

Brunner, L. (2007). Consuming Desires. $\quad$ Retrieved from http://www.graphicrepro.co.za/assets/2/pdf/37-FMCG.PDF

Burgess, S. M., \& Steenkamp, J. B. E. (2006). Marketing renaissance: How research in emerging markets advances marketing science and practice. International Journal of Research in Marketing, 23(4), 337-356. http://dx.doi.org/10.1016/j.jiresmar.2006.08.001

Chavan-Patil, D. (2012). Coloring consumer's psychology using different shades: The role of perception of colors by consumers in consumer decision making process. Journal of Business and Retail Management Research, 7(1), 60.

Chetthamrongchai, P., \& Davies, G. (2000). Segmenting the market for food shoppers using attitudes to shopping and to time. British Food Journal, 102(2), 81-101. http://dx.doi.org/10.1108/00070700010313071

DeLise, J. (2012). The charms of colour: The power to persuade can be only a shade or two away. Retrieved fromhttp://www.packagedesignmag.com/content/the-charms-color-the-power-persuade-can-be-only-a-shad e-or-two-away

Garber, L. L., Burke, R. R., \& Jones, J. M. (2000). The role of package colour in consumer purchase consideration and choice. Marketing Science Institute, 104, 1-48.

Hair, J. F., Black, W. C., Babin, B. J., \& Anderson, R. E. (2010). Multivariate Data Analysis (7th ed.). New Jersey: Pearson Prentice Hall.

Haller, K. (2013). Business Branding... does colour really matter? Retrieved from http://karenhaller.co.uk/blog/business-branding-does-colour-really-matter/

Hirschman, E. C., \& Holbrook, M. B. (1982). Hedonic Consumption: Emerging Concepts, Methods and Propositions. Journal of Marketing, 46(3), 92-101. http://dx.doi.org/10.2307/1251707

Jacoby, J., \& Kyner, D. (1973). Brand Loyalty versus Repeat Purchasing Behavior. Journal of Marketing Research, 10(1), 1-9. http://dx.doi.org/10.2307/3149402

Jones, M. A., Reynolds, K. E., Weun, S., \& Beatty, S. E. (2003). The product-specific nature of Impulse Buying tendency. Journal of Business Records, 56(7), 505-511. http://dx.doi.org/10.1016/S0148-2963(01)00250-8

Karbasivar, A., \& Yarahmadi, H. (2011). Evaluating Effective Factors on Consumer Impulse Buying Behavior. Asian Journal of Business Management Studies, 2(4), 174-181.

KissMetrics. (2014). How do colours affect purchases? Retrieved from http://blog.kissmetrics.com/color-psychology/?wide=1

Kollat, T. D., \& Willet, R. P. (1967). Consumer Impulse Purchasing Behaviour. Journal of Marketing Research, 4(1), 21-31. http://dx.doi.org/10.2307/3150160

Kruh, W., Morris, J., Debnam, N., Dolan, P., \& Gard, S. (2012). The Chocolate for Tomorrow, What today's market can tell us about tomorrow. Retrieved from https://www.kpmg.com/UK/en/IssuesAndInsights/ArticlesPublications/Documents/PDF/Market\%20Sector/ Retail_and_Consumer_Goods/chocolate-of-tomorrow.pdf

Kuikka, A., \& Laukkanen, T. (2012). Brand Loyalty and the role of hedonic value. Journal of Product and Brand Management, 21(7), 529-537. http://dx.doi.org/10.1108/10610421211276277

Labrecque, L., \& Milne, G. (2012). Exciting red and competent Blue: The importance of color in marketing. Journal of theAcademy of Marketing Science, 40(5), 711-727. http://dx.doi.org/10.1007/s11747-010-0245-y

Laird. (2014a). Laird Statistics: Friedman Test in SPSS. Retrieved from https://statistics.laerd.com/spss-tutorials/friedman-test-using-spss-statistics.php

Laird. (2014b). Laird Statistics: Mann-Whitney U Test in SPSS. Retrieved from https://statistics.laerd.com/spss-tutorials/mann-whitney-u-test-using-spss-statistics.php

Lee, J. \& Kacen, J. (2008). Cultural influences on consumer satisfaction with impulse and planned purchase decisions. Journal of Business Research, 61, 265-272. http://dx.doi.org/10.1016/j.jbusres.2007.06.006

Loyalty Square. (2010). Impact of Color. Retrieved from http://loyaltysquare.com/impact_of_color.php

Maholtra, N. K. (2010). Marketing Research: An Applied Orientation (6th ed.). New Jersey: Pearson. 
Mai, N., Jung, K., Lantz, G., \& Loeb, S. (2003). An Exploratory Investigation into Impulse Buying Behavior in a Transitional Economy: A Study of Urban Consumers in Vietnam. Journal of International Marketing, 11(2), 13-35. http://dx.doi.org/10.1509/jimk.11.2.13.20162

McConnell, J. (1968). The Development of Brand Loyalty: An Experimental Study. Journal of Marketing Research, 5(1), 13-19. http://dx.doi.org/10.2307/3149788

McPherson, D. (2005). The Psychology of Impulse Buying. Retrieved from http://specialtyretail.com/issue/2005/10/merchandising-and-marketing/visual-merchandising/impulse_buyin g_psychology/

NeuroRelay. (2012). Colour Psychology of Consumer Decision Making. Retrieved from http://neurorelay.com/2012/06/28/color-psychology-of-consumer-decision-making/

Petzer, D., \& De Meyer, C. (2013). Trials and tribulations: Marketing in Modern South Africa. European Business Review, 25(4), 382-390. http://dx.doi.org/10.1108/EBR-02-2013-0016

Rook, D. W., \& Fisher, R. J. (1995). Normative influences on Impulse Buying behavior. Journal of Business Research, 22(3), 23-27.

Rook, D. W., \& Gardner, M. P. (1993). In the mood: Impulse Buying's affective Antecedents. Research in Consumer Behavior, 6, 1-28.

Wellman, C., Kruger, F., \& Mitchell, B. (2005). Research Methodology. Cape Town: Oxford University Press.

Yakup, D., \& Jablonsk, S. (2012). Integrated Approach to Factors Affecting Consumers Purchase Behavior in Poland and an Empirical Study. Global Journal of Management and Business Research, 12(15), 64.

Zachariasen, A., \& Schofield, L. (2008). South Africa's Great Chocolate Rivalry. Retrieved from http://www.southafrica.info/business/success/ecape-chocolate.htm\#.U2PFvVFH_zI

Zeithaml, V. A., Berry, L. L., \& Parasuraman, A. (1996). The behavioural consequences of service quality. Journal of Marketing, 60(2), 31-46. http://dx.doi.org/10.2307/1251929

\section{Copyrights}

Copyright for this article is retained by the author(s), with first publication rights granted to the journal.

This is an open-access article distributed under the terms and conditions of the Creative Commons Attribution license (http://creativecommons.org/licenses/by/3.0/). 